\title{
El Problema de la Racionalidad en la Didáctica de La Ciencia
}

\author{
Francisco Covarrubias-Villa, M. G. Cruz-Navarro \\ Instituto Politécnico Nacional, Centro Interdisciplinario de Investigación para el Desarrollo Integral \\ Regional, Unidad Michoacán, Calle Justo Sierra, Núm. 28, Col. Centro, C.P. 59510, Jiquilpan, \\ Michoacán-México (e-mail: pancheco@prodigy.net.mx, lupitacruz63@hotmail.com)
}

Recibido Jun. 23, 2011; Aceptado Ago. 18, 2011; Versión final recibida Ago. 23, 2011

\begin{abstract}
Resumen
El objetivo de la investigación fue determinar la relación entre racionalidad didáctica y racionalidad de las teorías científicas. Para ello se analizaron las implicaciones epistemológicas y didácticas de las filosofías platónica y aristotélica, y la racionalidad de algunas teorías científicas aludidas en textos epistemológicos. Se encontró que las teorías científicas poseen una racionalidad determinada y cada teoría pedagógica sustenta una didáctica acorde con la racionalidad de esa teoría. En ocasiones coinciden la racionalidad didáctica y la de la teoría científica, pero a veces son inconmensurables. La solución es una didáctica sustentada en la misma racionalidad que la teoría científica estudiada. Esto puede determinarse por la filiación filosófica de los conceptos y categorías de la teoría pedagógica y las teorías científicas que serán analizadas en los cursos. Esta estrategia didáctica se contrapone a las basadas en la disciplinariedad, la interdisciplinariedad, la metadisciplinariedad y la transdisciplinariedad.
\end{abstract}

Palabras clave: racionalidad, teoría, didáctica, inconmensurabilidad, filiación filosófica

\section{The Problem of Rationality in the Didactics of Science}

\begin{abstract}
The objective of this research was to determine the relationship between didactic rationality and rationality of scientific theories. The epistemological and pedagogical implications of Platonic and Aristotelian philosophy and the rationality of scientific theories alluded to in epistemological texts are analyzed. It was found that scientific theories have a defined rationality and each pedagogical theory supports a didactics that is consistent with the rationality of that theory. Sometimes didactic rationality and that of the scientific theory coincide, but sometimes are immeasurable. The solution is a didactics supported in the same rationality that the scientific theory being studied. This can be determined by the philosophical affiliation of the concepts and categories of the pedagogical theory and the scientific theory to be discussed in the courses. This didactic strategy is in contrast to those based on disciplinarity, interdisciplinarity, metarationality and transdisciplinarity.
\end{abstract}

Keywords: rationality, theory, didactics, incommensurability, philosophical affiliation 


\section{INTRODUCCIÓN}

El problema de la racionalidad didáctica surge del análisis de la condición de inconmensurabilidad entre teorías científicas, llevado a la relación didáctica-teoría científica. El proceso de enseñanzaaprendizaje aparece al margen de cualquier racionalidad poseyendo una, generándose así la posibilidad de incompatibilidad con la teoría científica que se desea enseñar y aprender, convirtiendo a la cognición en un proceso irrealizable. Fue en las obras de Kuhn (1971) en donde se encontró planteado por primera vez el problema de la inconmensurabilidad. Después, al revisar los escritos de Koyré $(2000,2005 a, 2005 b)$ se vivió la sorpresa de que el problema de la inconmensurabilidad ya había sido percibido por él pero no denominado de esa manera, como sucedió también con el físico Bohr. Los planteamientos de Koyré sobre la física cualitativa de Aristóteles y su ininteligibilidad desde la física newtoniana, condujo a la revisión de los textos de Platón y Aristóteles que sustentan concepciones onto-epistemológicas contrapuestas, explicándose así el fenómeno de la inconmensurabilidad de las teorías científicas sustentadas en estos dos filósofos de la antigüedad clásica. Posteriormente se constató que los propios epistemólogos, filósofos, historiadores y psico-sociólogos de la ciencia, sustentan sus interpretaciones con base en la filiación a estos dos filósofos, del mismo modo que se hace en las ciencias naturales y sociales. Así sucede con Zemelman (2003), Popper (1972), Lakatos (1983), Feyerabend (2003), Koyré (2005b), Kuhn (1971), Bachelard (1971).

La didáctica de la ciencia parte del supuesto aristotélico de que el conocimiento científico se enseña y se aprende y que ello depende de la manera en la que se realiza el proceso de enseñanza-aprendizaje, dado que éste es un asunto de la racionalidad de la didáctica empleada para ello y no de la racionalidad de la teoría científica a la que pertenece el conocimiento que se quiere enseñar y aprender. La didáctica, al igual que las teorías científicas, está sustentada ontoepistemológicamente en la filosofía de Platón, en la de Aristóteles o en una combinación de ambas. Didácticamente tiene diferentes implicaciones cognitivas suponer la transmisibilidad del conocimiento o considerar a la reflexión como único camino a la episteme. No es lo mismo suponer que el conocimiento va de la razón a las cosas que de las cosas a la razón, por lo que se considera que la activación de la razón y la didáctica empleada en la formación científica, ha de sustentarse en la misma racionalidad en la que es construida la teoría científica estudiada.

La investigación que se presenta consistió en revisar en trabajos de epistemología, filosofía e historia de la ciencia, aquellos planteamientos de la racionalidad de teorías científicas que permitan percibir los problemas de la relación establecida entre didáctica y teoría científica, objeto de enseñanza-aprendizaje. La unión de la experiencia académica de los autores con la percepción del problema de la inconmensurabilidad entre teorías, permitió la delimitación del objeto y el diseño de su esquema de investigación, el cual sirvió de base para determinar las fuentes de información. Las fuentes de información se analizaron y se elaboraron y capturaron fichas de trabajo en una base de datos, a la que también se integraron fichas de reflexiones generadas por el análisis de las fuentes, por la docencia, por la participación en reuniones científicas o por otros medios. Posteriormente se diseñó el esquema de exposición cuya particularización condujo al diseño del guión de exposición. Éste sirvió para codificar las fichas de trabajo y posteriormente se redactó el texto del cual se extrajo el contenido del presente artículo.

\section{LA DIDÁCTICA POR TEORÍAS}

Las estrategias didácticas utilizadas para la formación de científicos en los estudios doctorales, son útiles para todos los niveles escolares posteriores al aprendizaje de la lecto-escritura. En la formación de sujetos racionales, no tiene sentido memorizar datos, pero sí lo tiene poder pensar desde diferentes teorías cómo y qué es la historia, la materia, la matemática, la energía, las sociedades humanas, etc. ¿Por qué no guiar el desarrollo del sujeto por el camino de la estructura de la teoría estudiando a cada una en su propia racionalidad? Aplicando los planteamientos de Platón a la educación preescolar, se puede considerar que a los niños no se les debe ocupar en el aprendizaje de la lecto-escritura, sino que deben estar abocados a la gimnástica y a la música porque la primera forma al cuerpo y la segunda al alma (Platón, 2009). A decir de Platón, Sócrates se oponía al uso de la violencia y a que a los niños se les cuenten fábulas, ya que éstas son un 
tejido de mentiras que pueden fácilmente quedar impresas en ellos de por vida (Platón, 2009). El niño que en preescolar estuvo plenamente orientado al desarrollo de habilidades motrices y sensoriales, puede ser orientado en la primaria en el aprendizaje de la lecto-escritura, la matemática, la gramática y las teorías científicas, en un proceso en el que se erradique la memorización y se centre la actividad pedagógica en la reflexión. A diferencia de la forma memorístico-disciplinaria que predomina en la actualidad, la escuela primaria buscaría inducir al alumno a la diferenciación entre las distintas maneras de interpretar la historia, los sucesos sociales y los fenómenos naturales, así como a navegar por el mundo de la abstracción matemática.

La enseñanza por teorías se organiza de manera tal que el nivel de complejidad se vaya incrementando en la medida en la que se asciende de grado escolar. En preescolar y primaria, se podría inducir al alumno al recurso de la imaginación, introducir en fantasías como la de viajar por una línea recta o curva, imaginar las explosiones nucleares del Sol, convertir las semillas en número, imaginar la gestación de una planta, etcétera. En secundaria y bachillerato las teorías serían tratadas con mayor detalle y a partir de la licenciatura hacerlo con gran precisión, organizando los programas de estudio de modo tal que en cada teoría se traten los siguientes puntos en el orden en el que aquí aparecen: 1) Biografía y condiciones históricas del constructor de una teoría. 2) Problemas filosófico-científicos discutidos en su época. 3) Concepción ontoepistemológica de la teoría y. 4) Categorías, conceptos y leyes de la teoría.

En la enseñanza de una teoría determinada se recomienda empezar por analizar la biografía de los principales constructores de una teoría y las condiciones sociales prevalecientes en el lugar y en la época en que se construyó, porque el conocer en qué ámbito se forma un científico y la problemática que se discute en una comunidad científica, permite comprender de qué manera está constituida su conciencia y la racionalidad que ésta asume porque se refleja como estructura de la teoría formulada. Esto se debe a que la cultura se expresa no sólo en ideas sino también en estructuras materiales determinadas.

La conciencia teorizante condensa referentes que existen en la época de su constitución, independientemente del momento histórico en el que fueron construidos, estableciendo así los criterios de intelección utilizados. "Todo conocimiento, incluso el más físico, sufre una determinación sociológica. En toda ciencia, incluso en la más física, hay una dimensión antroposocial. De golpe, la realidad antropo-social se proyecta e inscribe en el corazón mismo de la ciencia física" (Morin, 2006). Los objetos físicos generan estímulos y éstos son apropiados de distinto modo por diferentes sujetos, es decir, a partir de la forma de su conciencia. Los grupos de científicos tienen percepciones similares porque sus conciencias poseen una estructura semejante y una racionalidad adquirida en los procesos de formación como tales. La formación de científicos no es más que un proceso de incorporación de los referentes compartidos por una comunidad científica.

El siguiente paso es el consistente en discutir los problemas filosófico-científicos de la época en la que una teoría es construida. Se trata de identificar qué formulaciones teóricas estaban presentes en la agenda de los científicos durante el periodo en el que la teoría fue construida, qué ideas políticas, económicas, éticas, artísticas y religiosas se anidaban en las conciencias de sus contemporáneos y en la suya, etcétera, pero haciendo énfasis en las teorías. Sin embargo, Bachelard opina de manera opuesta. Para él, las teorías más audaces, es decir, las causantes de verdaderas revoluciones científicas son creaciones totalmente nuevas y discontinuas. Dice: "Otra forma de borrar las discontinuidades en el progreso científico supone atribuirle el mérito a la masa de trabajadores anónimos. Se dice que los progresos estaban «en el aire» cuando el hombre de genio los ha puesto al día. Entonces entran en consideración las «atmósferas», las «influencias». Cuando más lejos se está de los hechos, más fácilmente se evocan las «influencias». Las influencias se evocan continuamente a partir de los orígenes más lejanos. Les hacen atravesar continentes y siglos. Pero esta noción de influencia, tan cara al espíritu filosófico, no tiene ningún sentido en la transmisión de verdades y de descubrimientos en la ciencia contemporánea" (Bachelard, 1971). 
En el proceso educativo se trata de que el alumno piense los contenidos de la teoría con la misma racionalidad con la que esa teoría está construida, sin realizar traducciones a una racionalidad diferente, sin aceptación ni rechazo y sin enjuiciamientos de verdadera o falsa. Se trata de entender y no de juzgar. Las teorías no son verdaderas ni falsas, inferiores o superiores ni superables unas por otras. La formación de cadenas de teorías por su filiación filosófica, muestra la solución de enigmas pensables en la racionalidad de la que participan, pero la pertenencia de una teoría a una cadena de filiación diferente implica la ininteligibilidad de los enigmas de la otra haciéndola inconmensurable. El estudio del andamiaje categórico-conceptual de una teoría permite percibir la filiación filosófica de cada concepto, de cada categoría, estableciendo así la racionalidad total del andamiaje. Por ejemplo, el conocimiento del andamiaje de la teoría galileana permite percibir la recuperación de la matemática de Platón, que muestra el proceso histórico discontinuo de constitución de esa teoría cuya plenitud se encuentra en Newton.

Proponer el estudio de la filiación filosófica de los conceptos y las categorías de una teoría, es sostener que la enseñanza de una teoría requiere del conocimiento de su historia y de la filosofía implicada en ella. Pero la determinación de la estructura del andamiaje de una teoría, la filiación filosófica de sus conceptos y de sus categorías, la historia de las teorías integrantes de la cadena a la que la teoría está afiliada, la biografía y las condiciones histórico-sociales de la época de construcción de la teoría, todo ha de ser buscado, detectado y construido por el alumno y no por el profesor. Al profesor sólo corresponde guiar al alumno en la búsqueda. Después de que el alumno ha reconstruido el conocimiento de una teoría, ha de confrontar lo construido con las construcciones realizadas por sus compañeros y, después, por los historiadores, filósofos, sociólogos y psicólogos de la ciencia. Una vez que el alumno conoce diferentes teorías, percibirá la diferencialidad existente entre las racionalidades que sustentan a cada una de esas teorías. Se dará cuenta de que cada teoría ve el mundo de un modo determinado, que implica también un modo de conocerlo y que, por ello, en el estudio de la historia de la ciencia se perciben avances, pero sólo entre teorías afiliadas a la misma cadena filosófica, resultando inconmensurables con las teorías afiliadas a una cadena diferente a la suya.

\section{LA POLÉMICA}

\section{De la razón a las cosas o de las cosas a la razón}

Sócrates crea una didáctica dialogal denominada "mayéutica" consistente en formular y debatir preguntas entre interlocutores e inducir a la reflexión en la búsqueda del conocimiento de la verdad. Esta didáctica parte de que el maestro no puede inculcar el conocimiento al discípulo, dado que la mente no es un receptáculo en el que se pueda introducir la verdad; lo que procede es establecer un diálogo entre profesor y alumno para que, por medio de la reflexión, el alumno acceda al contenido de su alma, recordando lo que en ella escrito está. La anamnesis como medio para recordar no es otra cosa que la evocación a la razón, dado que al preguntar se induce a los sujetos a pensar y reflexionar lo ya conocido. Sólo así se llega a conocer la verdad de la naturaleza de las cosas. El socrático Platón considera que es propio del alma la reminiscencia, el carácter apriorístico del conocimiento y la existencia de ideas innatas, porque ella tiene escrito lo verdadero y todas las almas poseen la misma escritura, diferenciándose los sujetos por lo recordado y por lo leído de su alma. No se piensa, se recuerda, de ahí que la función de la educación sea la de generar las condiciones óptimas para que los sujetos puedan explorar sus almas, leerlas y hacer consciente su contenido. Dado que el lenguaje con el que el alma está escrita es el de las matemáticas, son ellas el medio para realizar la lectura y superar los niveles concupiscible e irascible en los que el alma puede estar atrapada.

Recordar lo ya escrito o recordar lo leído en vidas anteriores, son reminiscencias obstruidas por la corporeidad de los sentidos que la educación puede derrotar por medio de la dialéctica. "Así pues, el conocimiento es esencialmente iniciación, éxtasis, gnosis y purificación, pues se hunde en la profundidad de un tiempo que se arraiga más allá de las divisiones que separan y la multiplicidad que desune" (Brun, 2002). La escritura le es consustancial al alma inmortal que se encarna en diferentes cuerpos (Platón, 2007a), de modo tal que, lo que llamamos aprender, no es más que recordar algo que es sabido desde siempre (Platón, 2007b). Lo escrito en el alma no 
necesariamente es recordado por el sujeto como una función inmanente del cuerpo que esa alma ocupa. Para recordar es necesario someter a la conciencia a un proceso reflexivo racional o lectura del alma, que puede ser guiado por sujetos que han avanzado más en esa lectura: el profesor. "La esencia de la dialéctica es la mayéutica, que en griego significa alumbramiento y parto, en donde la parturienta no se opone a la comadrona sino que la criatura nace del cuerpo de aquella, de sus mismas entrañas. La comadrona sólo ayuda con sus dudas y sus preguntas" (Olarieta, 2008).

El partero cognitivo puede ser un profesor que por medio del diálogo cuestionador, conduce al alumno por el camino de la reflexión. Por eso, Platón hace decir a Sócrates: “...yo tengo de común con las parteras que soy estéril en punto a sabiduría, y en cuanto a lo que muchos me han echado en cara diciendo que interrogo a los demás y que no respondo a ninguna de las cuestiones que se me proponen, porque yo nada sé, este cargo no carece de fundamento. [...] Y se ve claramente que ellos nada han aprendido de mí, y que han encontrado en si [sí] mismos los numerosos y bellos conocimientos que han adquirido, no habiendo hecho yo otra cosa que contribuir con Dios a hacerles concebir" (Platón, 2007c). He aquí el centro de la didáctica platónica: la acción pedagógica consiste en que el profesor no transmita saberes al alumno, sino que simplemente le ayude a llegar a ellos por medio de la reflexión teórica. La mayéutica consiste pues en llegar a la anamnesis por medio de la dialéctica, pero el camino que la conciencia individual recorre para llegar a la verdad es largo y sinuoso. La dialéctica en Platón implica la posibilidad de construir universales por medio del agrupamiento de objetos (Platón, 2009). Dado que todas las almas tienen escrito lo mismo, todos los sujetos poseen la capacidad para recordar, para reflexionar racionalmente, sólo que algunos logran recordar muy poco. Nunca se aprende de otro, pues la ciencia se saca de la conciencia propia haciendo uso de la dialéctica (Platón, 2007b).

La concepción platónica del conocimiento como camino de la razón a las cosas, se contrapone a la concepción aristotélica que presenta a la sensación objetual como punto de partida y a la razón como punto de llegada. Para Aristóteles lo real existe con independencia de la conciencia, es racional y la razón es capaz de reproducirlo. Cuando los sujetos establecen la apropiación de lo real en el plano práctico utilitario, los sentidos perciben cualidades de los objetos particulares y cuando la apropiación que con lo real se establece es de carácter teorizante, la sensación no es más que el punto de partida o escala en el proceso de teorización que busca y construye lo universal con lo particular: "...la ciencia, es [...] la concepción de las cosas universales y de aquellas cuya existencia es necesaria" (Aristóteles, 2003).

En Platón los universales preexisten a lo real y se encarnan en los objetos sensibles; en Aristóteles, están contenidos en los objetos particulares y por son el medio para llegar a la ciencia que lo es de lo universal. En Aristóteles se trata de la inducción en la que el tránsito de lo particular a lo universal conlleva la construcción de conceptos y categorías. Los conceptos son la esencia de los objetos y las categorías la expresión de las cualidades despojadas del objeto concreto, pero ontológicamente existentes en ellos. A los conceptos y a las categorías se llega transitando de lo sensorial particular a lo racional universal y de ahí a la construcción de juicios y deducciones, es decir, al conocimiento lógico. Al colocar en el punto de partida a los objetos concretos, Aristóteles sentó las bases de la particularización del conocimiento y de la disciplinarización de la ciencia que está sustentada en 4 ideas centrales: 1) Que los universales son construcciones lógicas y no entes reales, dado que los objetos particulares ontológicamente poseen características que pueden repetirse entre ellos. 2) Que los objetos particulares observan características comunes que permiten su distribución entre disciplinas científicas distintas. 3) Que la división del trabajo científico se hace necesaria dados los enormes volúmenes del conocimiento científico producido, lo cual no implica la suposición de la existencia independiente de los objetos. 4) Que la construcción de teorías implica la alusión onto-epistemológica de universos determinados, generándose comunidades epistémicas constructoras de un lenguaje altamente especializado para comunicarse entre sus miembros.

Al igual que Platón, Aristóteles consideraba que el conocimiento verdadero es universal y abstracto y se encuentra en lo particular. La preeminencia ontológica de lo particular condujo a Aristóteles a dividir la filosofía en ciencias individuales, estableciendo un estatuto epistemológico 
que ha sido conservado hasta la actualidad. "La Física es la ciencia de un género de seres determinados; se ocupa de esta sustancia que posee en sí el principio del movimiento y del reposo. Evidentemente no es una ciencia práctica ni una ciencia creadora. El principio de toda creación, es en el agente, el espíritu, el arte o cierta potencia. La voluntad es en el agente el principio de toda práctica; es lo mismo que el objeto de acción y el de la elección. [...] Por lo tanto, hay tres ciencias teoréticas, la Ciencia matemática, la Física y la Teología" (Aristóteles, 2007). Más allá de la filiación filosófica con la que se reflexione, la verdad es un problema del conocimiento y no un problema de lo real, dado que las cosas, los objetos, no son falsos ni verdaderos sino que simplemente son, por lo que, finalmente, el problema se ubica en la relación que la conciencia establece con esos objetos, con esa realidad.

Inspirados en Aristóteles, Dilthey divide las ciencias en naturales y del espíritu; Rickert en nomotéticas e ideográficas (Arrillaga, 1987), Bunge en fácticas y formales con base en el objeto de estudio, en la forma de construir los enunciados y en el método (Bunge, 1969); De Gortari, marxista confeso, presenta la disciplinarización como resultante de la compleja estructura del universo (De Gortari, 1965); Olmedo, para quien existen tres grandes continentes del conocimiento: pensamiento, naturaleza y sociedad, sostiene que cuando estos continentes quedaron convertidos en ciencias, suprimieron la posibilidad de transferir los criterios de cientificidad de un continente a otro y marcaron la terminación de la historia de la filosofía (Olmedo, 1980). Para quienes consideran la disciplinarización de la ciencia como producto de la necesaria división del trabajo, la especialización laboral es un proceso asociado a la complejización de las sociedades en todos los ámbitos ocupacionales (Berger, 1968) y permite la centración cognitiva ante los grandes volúmenes de conocimiento existentes, cuya apropiación cognitiva resulta didácticamente imposible. Saber mucho de poco permite aguzar la intelección puntual de detalles que no es posible en visiones globales del mundo. "Una cultura científica sin especializaciones sería una herramienta sin punta, unas tijeras con los filos desgastados" (Bachelard, 1971). Kuhn asocia la disciplinarización de la ciencia con los procesos de construcción de teorías (Kuhn, 2000). Cuando una teoría es asumida por un grupo de científicos se inicia un proceso de solución de los enigmas propios de esa teoría, generándose una comunidad epistémica constructora de un lenguaje que comunica a sus miembros e impide la intromisión de extraños. "El número y la complejidad crecientes de los subuniversos los vuelve cada vez más inaccesibles a los profanos; se convierten en reductos esotéricos de una sabiduría 'hermética' [...] inaccesibles para todos los que no han sido iniciados en sus misterios" (Berger, 1968).

Kuhn establece un paralelismo entre la especiación biológica y la formación de comunidades epistémicas, a partir de la práctica investigadora en el interior de una teoría que, históricamente observada, evidencia cómo después de cada revolución científica hay más especialidades que las existentes antes de ella, haciéndolas inconmensurables aunque provengan de un tronco común (Kuhn, 2000). Martínez percibe claramente esta postura de Kuhn y explica que en él "...las revoluciones están frecuentemente asociadas con un aumento en el número de especialidades científicas requeridas por la adquisición continua de conocimiento científico. La proliferación de especialidades, de estructuras, prácticas y mundos es la que preserva la amplitud del conocimiento científico" (Martínez, 2010). En la proliferación de especialidades como proceso de especiación, se incluye en el lenguaje la multiplicación de concepciones del mundo, pero sin otorgarles la importancia que en realidad poseen. De ninguna manera se trata de la multiplicación infinita de visiones del mundo, una para cada subespecialidad, que resulten inconmensurables entre ellas, porque puede suceder que la falta de dominio del conocimiento de una subespecialidad sea interpretado como inconmensurabilidad sin serlo. Las teorías están afiliadas a las dos cadenas históricas de la filosofía: Platón y Aristóteles, sin que ello implique necesariamente la asunción tanto de la concepción ontológica como de la epistemológica de una sola de ellas en una teoría específica. Por el contrario, lo que se observa es la recuperación de componentes ontológicos de una filosofía con componentes epistemológicos de la otra.

Otro elemento participante en el proceso de especialización de la ciencia es el manejo de instrumentos propios de una teoría. En el interior de las comunidades epistémicas se trabaja por la precisión en las mediciones y el uso de instrumentos, pero no se trata de un proceso de creación de subespecialidades disciplinarias científicas, como lo suponen Kuhn (2000) y Miroli (2007), sino 
de universos concretos de percepción de las teorías, que implican o pueden implicar varios "campos disciplinarios" tradicionales. La teoría científica no construye una concepción ontológica original, sino una nueva combinación onto-epistemológica de las dos filosofías. Es el caso de pensar el tiempo, el espacio y el movimiento como contenido de objetos particulares tratados matemáticamente como despliegue óntico, uniendo a Aristóteles y Platón de una manera singular.

\section{La disciplinarización didáctico-cognitiva}

La clasificación de la ciencia siguió el camino trazado por Aristóteles, consistente en colocar los objetos particulares en una ciencia con base en una taxonomía morfológica cualitativa. Aunque se hayan construido teorías que implican universos ontológicos no determinables con los criterios taxonómicos aristotélicos, finalmente acabaron siendo ubicadas en alguno de los campos disciplinarios científicos ya establecidos. Este modelo de construcción de conocimiento de objetos particulares agrupados disciplinariamente en ciencias particulares, sirvió de base para el diseño de los modelos pedagógicos y para la organización académica de las escuelas. A pesar de las múltiples críticas recibidas y de un sinnúmero de modificaciones, el modelo disciplinario de integración de los curricula se mantiene sin salirse del marco gnoseológico aristotélico que implica varias cuestiones: 1) El conocimiento se construye. 2) Cada cuerpo crea su alma. 3) El alma se alimenta de las sensaciones. 4) Toda ciencia es susceptible de ser enseñada y toda cosa que es sabida puede aprenderse. Si esto es así, socialmente se deben crear las condiciones para que el proceso de constitución del alma se realice de la mejor manera. Así, las escuelas deben contar con instalaciones que faciliten la transmisión de conocimiento de los profesores a los alumnos, el curriculum ha de organizarse disciplinariamente, los programas de estudio se elaborarán por asignatura-disciplina, se contratarán los profesores mayormente especializados en cada disciplina y el personal administrativo más apto para dirigir las instituciones escolares.

Si la ciencia es dividida en disciplinas y éstas en temas, se da por establecida una sola racionalidad disciplinaria. Esta racionalidad única se atribuye a los diferentes temas considerados en el programa de estudios de la asignatura-disciplina y se mantiene en todos los cursos que de la misma se impartan. A pesar de que los temas del programa de estudios provengan de las teorías que serán estudiadas en el curso, son tomados como poseedores de la misma racionalidad y tratados de la misma manera. Esto se ve favorecido por el hecho de que, regularmente, el profesor de cada asignatura-disciplina asume la racionalidad de la teoría sustentada por sus formadores y vive la certeza de que todo supuesto conocimiento que no haya sido construido con ella, no posee carácter científico, de ahí que Feyerabend convoque a impedir que los científicos sean profesores (Feyerabend, 2003), como si los profesores profesionales estuviesen excluidos de la asunción de una sola racionalidad. La didáctica basada en la disciplinariedad científica, supone que el conocimiento puede ser enseñado o transmitido de una persona a otra, haciendo uso de los objetos concretos percibidos por los sentidos y que, por tanto, el aprendizaje es cuestión de estrategias didácticas integradas a una racionalidad neutral con respecto a las racionalidades sustentadas por las teorías científicas. En cambio, los partidarios de la unidad de la ciencia, a pesar de sustentar, en su mayoría, la concepción gnoseológica aristotélica del conocimiento, consideran que nadie puede transmitir a otro el conocimiento sino sólo propiciarlo. Evidentemente, la manera de concebir el conocimiento implica una postura didáctica y un modelo ideal de sujeto, de conformidad con el cual se quiere formar al educando. Así, según el énfasis que se dé a la formación literaria o a la científica, a la matemática o a la filosofía, al arte o a la técnica, se está dando forma a hombres distintos.

Intentando superar los problemas de la fragmentación, el disciplinarismo cognitivo y pedagógico ha propuesto la interdisciplinariedad, la multidisciplinariedad y la transdisciplinariedad. Sin embargo, las propuestas formuladas no toman en cuenta que las disciplinas científicas están integradas por teorías y que las teorías son construcciones onto-epistemológicas dotadas de una racionalidad afiliada a cadenas científico-filosóficas, que hacen inútiles estos esfuerzos pues, la existencia de racionalidades diferentes en las teorías agrupadas en cada disciplina, las torna inconmensurables ontológica y epistemológicamente hablando. Llámesele como se quiera, inter, multi o transdisciplinariedad son propuestas sustentadas en el principio de disciplinariedad que parte de una concepción fragmentarista del mundo en la que se estudian grupos de objetos reales 
toxonómicamente considerados con características semejantes, sin considerar que los objetos, los procesos y los fenómenos reales son percibidos del modo en el que son supuestos por la teoría desde la que son estudiados, por lo que la agrupación taxonómica de objetos es procedente en algunas teorías y extraña a otras.

Si cada teoría requiere de una didáctica ad hoc, la organización disciplinarista del curriculum conlleva el problema de que la formación del profesor se dio con base en la racionalidad de una de las teorías agrupadas en la disciplina científica que imparte, por lo que, de inmediato, aparece el problema de que todas las teorías son tratadas como si pertenecieran a una misma racionalidad, aún aquellas sustentadas en racionalidades inconmensurables entre sí. El profesor podría no darse cuenta de la contradicción en la que su práctica docente se debate, debido a que elevó a nivel de racionalidad científica la racionalidad de la teoría en la que él se formó, percibiendo la ciencia disciplinaria como un proceso permanente de progreso y acumulación de conocimiento, libre de rupturas o revoluciones. Este problema de la inconmensurabilidad entre teorías y entre racionalidades conlleva otro: el de la correspondencia de la racionalidad de la didáctica utilizada -que pertenece a una teoría pedagógica que, a su vez, está afiliada a una filosofía-, con la racionalidad de las teorías incluidas en la disciplina que se imparte. Es casi seguro que ninguno de estos dos problemas es percibido por la inmensa mayoría de los profesores de ciencias y que didácticamente se proceda con una racionalidad consecuente.

La práctica educativa basada en la disciplinarización de la ciencia y en el supuesto aristotélico de la posibilidad de aprendizaje de la ciencia, intenta formar conciencias teorizantes por medio de la transmisión del conocimiento en forma de saberes. Sin embargo, el alumno cuya conciencia opera con criterios propios de la empiria, memoriza los saberes pero no la lógica con la que fueron construidos, conduciendo a la obtención de altas calificaciones siendo incapaz de generar pensamiento alguno. En cambio, como lo plantea Platón, si el alma tiene escrita la verdad y todo sujeto está dotado de alma, todo sujeto tiene la posibilidad de transitar a la conciencia teorizante: “...todos poseen en su alma la facultad de aprender, con un órgano a ello destinado; que todo el secreto consiste en apartar a ese órgano, con toda el alma, de la visión de lo que nace, hacia la contemplación de lo que es, hasta que pueda fijar sus miradas en lo que hay de más luminoso en el ser..." (Platón, 2009). Lo que lo impide, son las condiciones sociales de existencia de los sujetos, entre otras, el predominio del criterio social de la empiria que alcanza a las propias instituciones educativas. El propio Aristóteles se opone a la educación técnica profesional “...porque tal formación no estaría orientada a beneficiar al hombre, sino a las cosas que sirven a los hombres, mientras que la verdadera educación pretende que los ciudadanos sean verdadera y plenamente hombres" (Reale, 2007).

La abstracción empírica propuesta por Aristóteles conlleva el problema de la resistencia a abandonar la base práctico-utilitaria de la existencia, generándose desviaciones en el proceso educativo por las tendencias a asirse a lo concreto y a eludir la elevación a la razón. Otro aspecto negativo de la propuesta pedagógica aristotélica es la que se refiere a las implicaciones represivas que la transmisión de conocimiento conlleva, pues, quien posee conocimiento posee autoridad y obliga al alumno a memorizar lo que él dice, impidiéndole el desarrollo de la facultad reflexiva. Tómese en cuenta que no existe ni puede existir filósofo o científico alguno despojado de una capacidad reflexiva altamente desarrollada.

Platón transforma la dialéctica socrática en método científico y en la alegoría de la línea, describe que la dialéctica se lleva a cabo en dos formas: la ascendente que parte de unas ciencias particulares y llega a la ciencia de lo general (las ideas) y la descendente que parte de la idea y llega a lo particular. Con respecto a la primera, Platón dice: “...ciencia a la primera y más perfecta forma de conocer, conocimiento razonado a la segunda, fe a la tercera, conjetura a la cuarta, comprendiendo a las dos últimas bajo el nombre de opinión, y a las dos primeras bajo el de inteligencia, de suerte que lo que nazca sea objeto de la opinión, y lo que es, de la inteligencia; y que la inteligencia sea respecto de la opinión, la ciencia respecto de la fe, el conocimiento razonado respecto de la conjetura, lo que la esencia es respecto de lo que nace" (Platón, 2009). La descendente se da una vez que el sujeto asciende a la forma más perfecta del conocimiento, es decir, a la ciencia: tiene la experiencia con los objetos sensibles, surge la duda, se lleva a cabo 
la investigación y por consiguiente, se llega a la generación de ideas para dar una interpretación científica de lo particular. En términos pedagógicos se puede tener contacto con la ciencia de dos maneras: una, cuando por medio de la razón se llega al nivel más alto del conocimiento (la ciencia) (ascendente) y, la otra, cuando una vez que se posee la ciencia se formulan ideas (la teoría) (descendente). El hombre puede pensar y surgen las ideas; al contacto físico con la realidad se establece una relación razonada de modo tal que la conciencia emitirá una interpretación teórica o científica de la realidad.

Platón sostiene que el sujeto necesita pasar por un proceso educativo que consiste en ser guiado al nivel más alto de la razón, es decir, al conocimiento científico (la ciencia). En este proceso se requiere de un educador y de un educando (maestro-alumno), uno que induzca y guie a la reflexión y otro que piense (Platón, 2007c). Porque así como la gimnasia ejercita al cuerpo para mantenerse saludable, el estudio ejercita a la razón y evita la ignorancia aprovechando lo que naturalmente existe en ella. "El alma misma, ¿no adquiere las ciencias, no se conserva, y no se hace mejor por el estudio y por la meditación, que son movimientos; mientras que el reposo y la falta de reflexión y de estudio la impiden aprender nada, y la hacen olvidar lo que ha aprendido? [...] ¿El movimiento es un bien para el alma como para el cuerpo, y el reposo un mal?" (Platón, 2007c). Si se tomara como base la dialéctica platónica en los procesos educativos, seguramente se tendrían alcances no imaginados dado que, cuando el sujeto en su experiencia con el mundo físico percibe un problema y surge la duda en él, la dialéctica lo conduce a pensar y después emitir un juicio u opinión pues, pensar, es "un discurso que el alma se dirige a si [sí] misma sobre los objetos que considera [...] me parece que el alma, cuando piensa, no hace otra cosa que conversar consigo misma, interrogando y respondiendo, afirmando y negando, y que cuando se ha resuelto, sea más o menos pronto y ha dicho su pensamiento sobre un objeto sin permanecer más en duda, en esto consiste el juicio. Así pues, juzgar, en mi concepto es hablar, y la opinión es un discurso pronunciado, no a otro, ni de viva voz, sino en silencio y a sí mismo" (Platón, 2007c). Esta definición expresa que, para que un sujeto aprenda a pensar, es necesario que sea inducido a la reflexión; que los discípulos no son simples receptáculos de ideas y; finalmente, que el método (la dialéctica) empleado sea de forma ascendente y descendente.

\section{La práctica docente}

Llevados a la práctica docente, estos planteamientos son traducidos del siguiente modo: 1) El docente para ser educador necesita ascender al mundo de las ciencias (teorías) en su proceso formativo. 2) Una vez que el educador ascienda, educará de la forma como fue educado. 3) Empleará como método pedagógico el sistema de enseñanza dialogal. 4) Tendrá como objetivo principal el hacer pensar al alumno, inducirlo a la reflexión, al ejercicio de la razón para llevarlo al mundo de las ideas y. 5) Percibirá al alumno como un interlocutor para aprender recíprocamente. Platón considera que el aprendizaje no es fácil y que incluso puede resultar doloroso, porque se requiere de esfuerzo, dedicación y constancia para superar las opiniones cotidianas y elevarse a lo verdadero. Es observable que en la historia de la humanidad, la inmensa mayoría de los sujetos se quedan en el nivel inferior del pensamiento (doxa) y que son unos cuantos los que ascienden al nivel superior (episteme). Tal vez esta tendencia se deba a que el sujeto que determina ingresar al mundo del conocimiento científico, requiere de "la sagacidad necesaria para el estudio de las ciencias, y la facilidad para aprender. Porque el alma desmaya mucho más pronto ante las dificultades de las ciencias abstractas que ante las de la gimnástica, porque el trabajo es sólo para ella, y el cuerpo no lo comparte" (Platón, 2009).

Platón piensa que la facultad de saber es consustancial a todos los sujetos (Platón, 2009) y que desde temprana edad se debe educar en disciplinas que activen la capacidad reflexiva. Dice: "Desde su más tierna edad, por tanto, debemos aplicar a nuestros alumnos al estudio de la aritmética, de la geometría y de las demás ciencias que sirven de preparación a la dialéctica; pero hay que desterrar de las formas de la enseñanza todo lo que pueda sonar a coacción y a traba. [...] Porque un espíritu libre no debe aprender nada como esclavo. [...] las lecciones que por fuerza se hacen entrar en un alma no quedan en ella" (Platón, 2009). La concepción platónica considera que el camino educativo que conduce a la razón es el de la reflexión y, por tanto, el de la lógica y la matemática. Coincidentemente, Bachelard plantea: "la doctrina de la razón está basada en la 
aritmética elemental. [...] La pedagogía de la razón debe aprovechar todas las ocasiones para razonar. Debe buscar la variedad de razonamientos, o mejor aún las variaciones del razonamiento. Ahora bien, las variaciones del razonamiento son numerosas en las ciencias geométricas y físicas; se unen a la dialéctica de los principios de razón, a la actividad de la filosofía del no" (Bachelard, 1971). Y deslindándose parcialmente de Platón, agrega: "Hay que aceptar la lección. La razón una vez más debe obedecer a la ciencia. La geometría, la física, la aritmética son ciencias; la doctrina tradicional de una razón absoluta e inmutable es sólo una filosofía caduca" (Bachelard, 1971).

Platón y Aristóteles colocan a la razón en la cumbre del desarrollo humano, pero las implicaciones pedagógicas de sus concepciones conducen a didácticas contrapuestas. En Platón el profesor es un guía del alumno; en Aristóteles es un transmisor de conocimiento. Si el alumno asume el papel de receptor de conocimiento, aun cuando se trate de la transmisión de referentes teóricos, se enfrentará el problema de que traduce los referentes que recibe a la manera en la que opera su conciencia, que no es otra que la empírica. La acumulación de referentes de un modo determinado de apropiación de lo real, no implica la adquisición de la forma de conciencia a la que esos referentes pertenecen, por lo que a eso se deben los fracasos frecuentes de los estudiantes de carreras universitarias de carácter investigativo, al no estar dotados de una conciencia crítica y reflexiva. La facultad reflexiva es común a todos los sujetos, pero sólo la desarrollan aquellos que fueron educados para ello. Sin embargo, son pocos los sujetos que hacen transitar sus conciencias al plano racional, dada la aplastante presencia empírica de la vida cotidiana, que ocasiona que los propios profesores queden aprisionados en ella. El profesor no puede proceder socráticamente de manera mayéutica, porque ni siquiera lo comprende; no sabe que sólo buceando en la razón se pueden generar conciencias racionales, dado que él mismo no ha logrado acceder a ella.

La escuela y los profesores se ocupan exclusivamente en decirle al alumno qué piense, pero no lo enseñan a hacerlo. Del mismo modo que para aprender un deporte se tiene que desarrollar gimnásticamente el cuerpo y que para apreciar la música se tiene que ejercitar el oído, para aprender a pensar es necesario someter al sujeto a una gimnasia de la razón, que debe empezar desde temprana edad. "Desde los primeros grados hay que ir educando no sólo en la matemática propiamente dicha, sino también en el razonamiento lógico y deductivo, que es la base de la matemática, pero que es también imprescindible para ordenar y asimilar toda clase de conocimiento" (Santaló, 1997). El pensamiento abstracto puede ser tomado como punto de llegada y no como de partida. La matemática no tiene porque ser inicialmente abordada abstractamente, pero tampoco ha de ser reducida a la solución de problemas práctico-utilitarios; puede ser utilizada para realizar reflexiones de poca complejidad como las referentes a agrupamientos simbolizados por la unidad, la inducción por agrupamientos cualitativos, la expresión cuantitativa de cualidades, etcétera. Se trata de ir aprendiendo a razonar sin detenerse en el registro memorístico de datos. En la medida en que se asciende de grado escolar, se pueden ir tratando procesos más complejos que requieren mayor grado de abstracción, cuidando que el grado de maduración de los sujetos corresponda con el grado de complejidad de lo tratado. Como plantea Sastre: “...el papel del maestro no debe ser el de transmisor de conocimientos, sino el de intermediario del pensamiento del niño y la realidad y ello lo consigue observando primero cual es la forma de pensar de éste, y, luego, creando situaciones de contraste destinadas a engendrar contradicciones que el niño pueda sentir como tales y que le inciten en encontrar una solución mejor" (Sastre, 1996).

\section{CONCLUSIONES}

De las reflexiones y planteamientos discutidos se pueden extraer las siguientes conclusiones: i) La disciplinariedad científica está basada en el pensamiento de Aristóteles y en ella los objetos reales se presentan como objetos de conocimiento de las ciencias. De este modo, territorios de la realidad integrados por determinado tipo de objetos, constituyen el campo de estudio de una disciplina científica; ii) Si un objeto real es incluido en el territorio de diferentes disciplinas, aparece una anomalía onto-epistemológica que quiere ser superada por medio de la interdisciplinariedad, la multidisciplinariedad y la transdisciplinariedad que, por seguir aprisionadas en la racionalidad 
disciplinarista, no resuelven el problema sino que lo agudizan por no considerar que las disciplinas científicas no son más que agrupamientos de teorías sustentadas en racionalidades diferentes; iii)

El conocimiento a profundidad de varias teorías hace consciente al científico de su ubicación investigativa, de la filiación filosófica de la teoría en la que realiza su práctica científica y de la estructura de la racionalidad de la teoría en la que sustenta su práctica, lo cual lo coloca en posición favorable para resolver enigmas o para formular nuevas teorías; iv) El científico formado exclusivamente en el interior de una teoría, casi nunca conoce la ubicación y los alcances del trabajo que realiza, cierra su consciencia a otras racionalidades y todo planteamiento que provenga de una racionalidad distinta es considerado por él como no científico; v) Cada racionalidad requiere de su respectiva didáctica. La enseñanza de la racionalidad en la que se sustentan las teorías científicas permite el desarrollo de la capacidad teorizante de los científicos y la producción teórica; vi) La enseñanza de la ciencia por teoría es la didáctica más apropiada, pues abre la posibilidad de hacer coherente la racionalidad didáctica con la racionalidad de la teoría científica que se enseña y aprende, pero su aplicación implica enfrentar serios problemas como son la modificación de los planes de estudio, la adecuación de instalaciones y la capacitación de profesores en la nueva didáctica.

\section{REFERENCIAS}

Aristóteles, Ética nicomaquea, 1ª edición, 216-221, Losada, Buenos Aires, Argentina (2003).

Aristóteles, Metafísica, 19a edición, 129-131, México, Porrúa (2007).

Arrillaga Torrens, R., La naturaleza del conocer, $1^{\mathrm{a}}$ edición, 12, Paidós, Buenos Aires, Argentina (1987).

Bachelard, G., Epistemología, 1ª edición, 143-187, Anagrama, Barcelona, España (1971).

Berger, P. y T. Luckmann, La construcción social de la realidad, 1ª edición, 114-149, Amorrortu, Buenos Aires, Argentina (1968).

Brun, J., Los presocráticos, $1^{\text {a }}$ edición, 104-105, Publicaciones Cruz, México, México (2002).

Bunge, M.A., La ciencia. Su método y su filosofía, 1ª edición, 11-16, Siglo Veinte, Buenos Aires, Argentina (1969).

De Gortari, E., Introducción a la lógica dialéctica, $3^{a}$ edición, 17, Fondo de Cultura Económica, México, México (1965).

Feyerabend, P., Tratado contra el método, 4ª edición, 209, Tecnos, Madrid, España (2003).

Koyré, A., Del universo cerrado al universo infinito, 10ª edición, 152-154, Siglo XXI, México, México (2005a).

Koyré, A., Estudios de historia del pensamiento científico, 25ª edición, 150-186, Siglo XXI, México, México (2000).

Koyré, A., Estudios galileanos, 9ª edición, 147-202, Siglo XXI, México, México (2005b).

Kuhn, T.S., El camino desde la estructura, $1^{\text {a }}$ edición, 147-148, Paidós, Barcelona, España (2000).

Kuhn, T.S., La estructura de las revoluciones científicas, $1^{\text {a }}$ edición, 33-246, Fondo de Cultura Económica, México, México (1971).

Lakatos, I., La metodología de los programas de investigación científica, $1^{\text {a }}$ edición, 9-179, Alianza Universidad, Madrid, España (1983). 
Martínez, M.L., La metáfora evolucionista en Kuhn, (2010),

http://galileo.fcien.edu.uy/metafora_evolucionista_kuhn.htm. Acceso: 19 de mayo de 2011.

Miroli, A.G., Filtros epistémicos y alternativas relevantes, Andamios, ISSN: 1870-0063 (impreso), 4(7), (2007).

http://redalyc.uaemex.mx/redalyc/src/inicio/ArtPdfRed.jsp?iCve=62840702\&iCveNum=7890

Acceso: 19 de mayo 2011.

Morin, E., El método. La naturaleza de la naturaleza, $7^{\text {a }}$ edición, 23-24, Cátedra, Madrid, España (2006).

Olarieta Alberdi, J.M., Contra la corriente el origen de la dialéctica en la Grecia antigua, Nómadas, ISSN: 1578-6730 (en línea), julio-diciembre(20), 2008.

http://redalyc.uaemex.mx/redalyc/src/inicio/ArtPdfRed.jsp?iCve=18102015\&iCveNum=10762 Acceso: 12 de abril 2011.

Olmedo, R., El antimétodo: Introducción a la filosofía marxista, 153-154, Joaquín Mortiz, México, México (1980).

Platón, Fedón o del Alma, Diálogos, 30ª edición, Vol. 1, 561-562, Porrúa, México, México (2007a).

Platón, Menón o de la virtud, Diálogos, 30ª edición, Vol. 1, 299-305, Porrúa, México, México (2007b).

Platón, Teetetes o de la ciencia, Diálogos, 30ª edición, Vol. 1, 424-478, Porrúa, México, México (2007c).

Platón, La República, Diálogos, 31ª edición, Vol. 2, 44-174, Porrúa, México, México (2009).

Popper, K.R., Conjeturas y refutaciones. (El desarrollo del conocimiento científico), $1^{\text {a }}$ edición, 57129, Paidós, Barcelona, España (1972).

Reale, G., Introducción a Aristóteles, $1^{\text {a }}$ edición, 42-123, Herder, Barcelona, España (2007).

Sastre, G. y M. Moreno, Descubrimiento y construcción de conocimientos, $1^{\text {a }}$ edición, 104, Gedisa, Barcelona, España (1996).

Santaló, L.A., "Matemáticas para no matemáticos" en Didáctica de matemáticas, $1^{a}$ edición, Paidós, 22-34, México, México (1997).

Zemelman, H., Los horizontes de la razón, 2a edición, Tomo I: 27-196; Tomo II: 99-164, Anthropos, Barcelona, España (2003). 